cavil at it. We think, therefore, that both from this and from the post-mortem evidence the proof is the same. Clinically the disease was tuberculous meningitis, and had been diagnosed as such by Dr. M. C. Hayward of Abingdon, who sent the child to the infirmary, and by one of us in the wards (W. T. B.) before the report on the cerebro-spinal fluid was made. The presence of lesions in the choroid is suggestive of tuberculosis, but their real nature was open to doubt.

From an examination of the literature Martin, by the application of his criteria, has been able to say that 20 undoubted cases have been recorded since 1894. Since the appearance of Martin's papers two further records have appeared, one by Allaria ${ }^{2}$ in which a child, aged 5, had symptoms for three weeks of meningitis which slowly abated, leaving some contracture which finally passed off. The child attended school for one month, but the meningeal symptoms reappeared and death occurred in four weeks. At the necropsy there was basal meningitis, and there were many recent grey granulations on the pia mater of the base of the brain and along the Sylvian fissure, and on the vault. There was also miliary tuberculosis of the lungs, spleen, liver, and caseous peribronchial glands. of 19 cases examined in the literature by Allaria he allows 10 to be genuine recoveries. A yet later case has been recorded by de Renzi. ${ }^{3}$

0xford.

\section{THE \\ RELATIONSHIP BETWEEN MOVEABLE KIDNEY AND CHRONIC COLITIS.}

\section{BY J. LIDDELL, M.D. EDIN.}

THE frequent association of moveable kidney and chronic colitis has been recognised by various observers, and most of them consider there is a causal relationship between the conditions. There is, however, a diversity of opinion as to the nature of this relationship, and as to the true connexion of the one to the other, Debore ${ }^{1}$ and other observers hold the view that the nephroptosis is not only a cause of enterocolitis, but is the most frequent cause. Others, again, hold the opposite view, and consider that nephroptosis is due to colitis. As my experience of these cases has been considerable in recent years, I am venturing to deal briefly with the question, and to give my view básed on the results of my observations.

The frequency with which moveable kidney occurs in cases of colitis is remarkable. Both kidneys may be moveable, but that is not often the case ; more generally it is one kidney, and in a large percentage it is the right one. I have seldom seen a patient with nephroptosis who is not also affected with colitis, even in those in whom the loose kidney was attributed to an accident. The exceptions have been chiefly in cases of visceroptosis where the kidneys have become displaced along with the other viscera. Nephroptosis is a fairly common condition, and like enterocolitis it is much more common than many of the profession have yet realised. It is a troublesome complication in colitis, especially when the kidney is freely moveable and floats about the abdomen or becomes fixed by adhesions.

A question which naturally occurs is this: What causes the kidney to become loose? In considering this let us remember that the organ lies behind the peritoneum, embedded in, and chiefly supported by, a considerable amount of adipose tissue which is closely adherent to the surface of the kidney. Another point to note is that the tissue of the kidney is easily lacerated. Now when a moveable kidney is exposed it is found to be devoid, or almost deroid, of fat, so that when it becomes displaced it is apparent that it becomes separated from its enveloping mass of fat. Cases are recorded where displacement of the kidney dates from a fall, but it is impossible that' it could be detached from its closely adherent envelope from such a cause only, as a force sufficient to cause such a result would produce serious damage to the kidney as well. There is no

${ }^{2}$ Allaria: La Pediatria, 1909, abstr. in Brit. Med. Jour., 1909, ii., Epit. 313.

$3 \mathrm{E}$. de Renzi : Di un Caso di Meningite tubercolare seguito da Guarigione, Boll. d. clin., Milano, 1910, xxvii., 367. evidence of such injury in these reported cases, nor was there in any of my cases where the displaced kidney was attributer to a fall. Therefore, it is evident that previously to the accident it had become separated by some means from it: attachment, and remained in situ until the accident. displaced it.

Moveable kidney very rarely occurs in those who are well nourished and show no appreciable loss of fat. In nearly al the patients I have seen with the combined conditions thers was distinct evidence of auto-intoxication due to colitis. Im a large proportion there was considerable diminution of the general fat, the patients being thin and sometimes emaciated. This must have been due to a solvent effect of the toxin pro. duced in the intestine upon the fat, or to a non-absorption of fat during digestion, or to both. The perinephric fat evidently participated in this loss; thus the organ was loosened, and gravitation and various movements caused it to descend anc produce the condition we call moveable or floating kidney

Let us next consider the effect of the loose kidney upor the intestine. Often in colitis the loose kidney by its. weight displaces the intestine and so produces an enteroptosis which in turn causes stasis of the contents, a condition which tends to keep up the colitis. Thus we car understand, should the kidney become displaced in a patient with a previously healthy intestine, how it can eventually produce colitis. First, the weight of the kidney displaces and also irritates the colon. Next, in the intestinal contents, whose passage is delayed, increasec putrefactive changes take place, the products of which irritate the mucous membrane and cause catarrh of that structure. To trace the sequence of events is sometimes difficult, but my experience has led me to the conclusior. that in nearly all cases colitis precedes and causes the nephroptosis through the action of the colitio toxis on the fat as already stated.

Many cases of colitis are unrecognised because there is no history of the voidance of mucus. As I have already mentioned in previous articles on this ailment, ${ }^{2}$ the absence of this history is immaterial, because mucus is so often passed coated with, or embedded in, fæces as to be ordinarily unrecognisable. Should the patients have the signs and symptoms I have there described then the presence of colitis is certain. ${ }^{3}$

The diagnosis of moveable kidney is usually easily made. unless the kidney has slipped back to its proper position at the time of the examination, and then several examinations may be necessary before we are able to determine that it exists. In all cases of colitis it is essential to ascertain if the kidneys are displaced, and if so whether they are free or are fixed by adhesions in an abnormal position.

The treatment of the two conditions may be carried on simultaneously. First as to the colitis. Briefly, my treatment consists of intestinal douches with one of the Harrogate sulphur waters, these being singularly and peculiarly efficacious in this disease. This is combined with abdominal massage and exercises given by experienced Swedish gymnasts. Then special dieting is essential. By these means digestion and nutrition are improved, the tone of the tissues is increased, also emaciated patients gain in weight, and a deposition of fat takes place. Results appear te indicate that the kidney fat is also increased.

The improvement effected by the treatment for colitis. helps materially in supporting the kidney. The abdomina muscles are the natural muscular belt for supporting the abdominal organs. These muscles are developed and strengthened by this treatment, and by giving the abdominai viscera increased support tend to maintain the kidney in its. proper position. Patients are sometimes advised to wear trusses or belts with pacls, but the pressure of these causes atrophy of the muscles, and therefore they ought to be used only as a temporary means of treatment. The patient should be taught how to replace the kidney, and instructed to replace it always on going to bed. By thus keeping it in position the area of movement becomes contracted and not so easily traversed by the kidney. Incredible as it may seem, I have seen kidneys that could be nacved? quite freely from the posterior to the anterior abdomina? wall, eventually become fixed in their natural position.

2 Liddell : Some Clinical Observations on Muco-membranous Colitis

The LANCET, May 18th, 1907.

Theronic Maceit Colitis, Practitioner, Uarch, 1911. 
But should these means fail, and the prolapsed kidney cause a continuance of the colitis, the question of nephropexy has to be considered. This operation is not always successful in permanently anchoring the kidney, but when it is, improvement in the colitis usually follows, though in my experience a cure of the colitis has never resulted. In this it resembles appendicectomy where the appendicitis was the result of colitis. In such a case the diseased appendix is a source of irritation, and its removal is generally followed by an amelioration of the condition of the colon, but does not bring about a cure of the colitis. It is essential here, as it is after nephropexy, to have systematic treatment for the colitis before its cure can be effected.

Harrogate.

\section{PERFORATING APPENDICITIS OF BILHARZIAL ORIGIN.}

\section{BY H. TEMPLE MURSELL, M.B., M.C. Edin. F.R.C.S. EuIN.,}

EXTRA HONORARY SURGEON, JOHANNESBURG HOSPITAL.

THE following case appears worthy of record, as it is the only one I am able to discover in which an appendicitis of bilharzial origin has caused perforation and has been operated upon.

The patient, a South African native about 25 years of age, from Natal, was admitted to Johannesburg Hospital suffering from an "acute abdomen" of about two and a half days' duration, the condition being diagnosed as an acute perforating appendicitis with widely spread peritonitis and pus. There was an indefinite history of abdominal pain of recurrent type extending over a considerable period, but as is usual with native patients the actual duration of symptoms, or when symptoms first arose, could not be ascertained. The abdomen

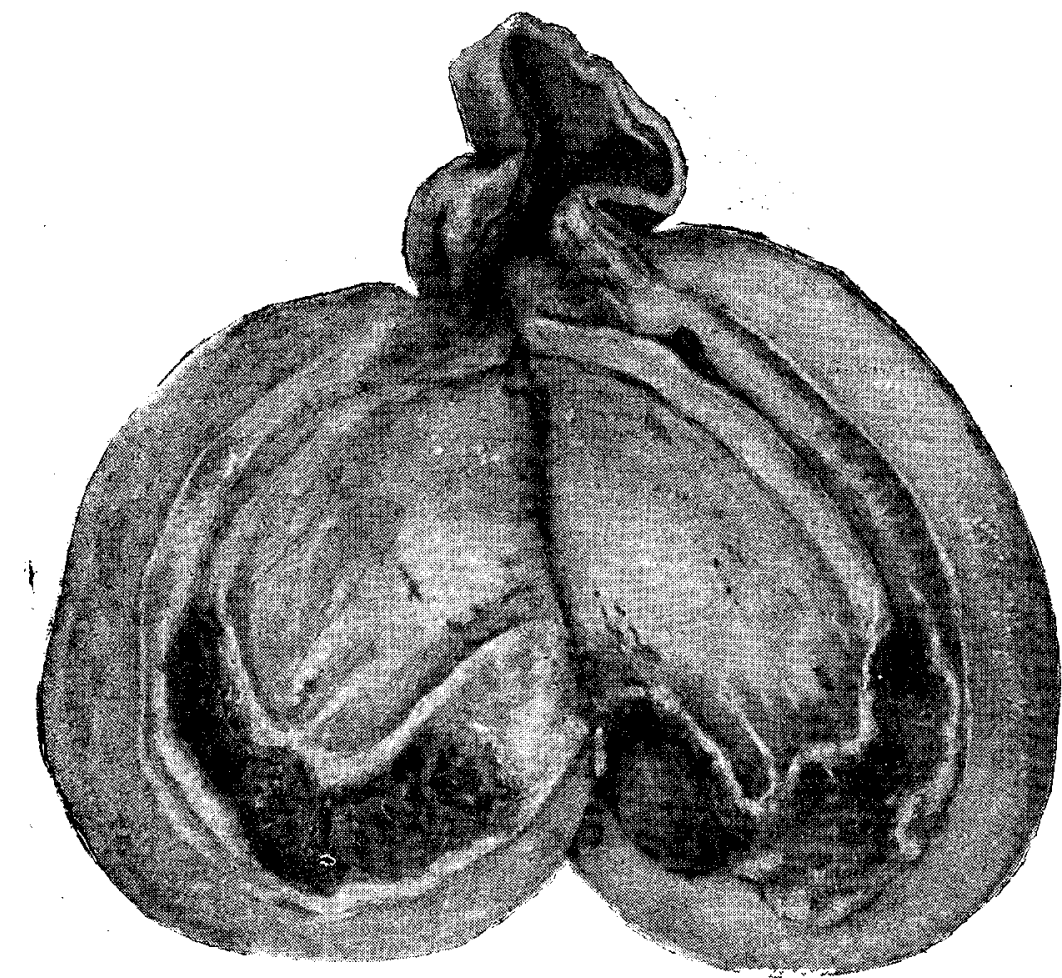

Reprorluction of a water-colour sketch of the sperimen.

was opened in the usual way over the region of the appendix, and a large quantity of foul-smelling pus escaped. There were no limiting adhesions and the whole pelvis seemed full of pus. In the appendix region a large moveable lump was felt attached to the cæcun. The accompanying diagram is rather smaller than the actual specimen. The lump was undoubtedly appendix and was attached to the cæcum by a short stalk of fairly healthy appendicular tissue as shown in the diagram. At the hinder part of the main mass was a perforation. The whole appendix was removed in the usual fashion, and the pus area was freely drained. The patient, in spite of his very serious condition, made an excellent recovery.

On section of the mass remored the proximal portion of the appendix was fairly healthy, showing merely catarrh. On following this proximal portion of the lumen down the walls of the organ were found enormously thickened, the thickening affecting mainly the muscular coats. A large stercolith occupied this portion of the lumen, and there was also here a perforation into the general peritoneal cavity.

The specimen was submitted to Dr. J. C. Mitchell, pathologist to the hospital. The thickening proved to be from increase of fibrous tissue, apparently of chronic inflammatory origin. In this tissue were embedded bilharzial ova, which it seems fair to assume were the primary causal agent in the inflammatory process.

My friend, Dr. George Turner, medical officer to the Witwatersrand Native Labour Association, whose opportunities for pathological investigation in South African natives is probably unrivalled, assures me that bilharzial infiltration of the appendix is not uncommon in South African natives, though he has not seen one in which such great changes have been induced as in the present instance, nor one in which perforation had occurred.

The specimen is in the Museum of the Royal College of Surgeons of England. The diagram was made from a very excellent colour drawing of the specimen by Messrs. Shiells and Ford.

\section{THE INTRAVENOUS INJECTION OF PARALDEHYDE.}

BY H. L. C. NOEL, M.R.C.S. ENG., L.R.C.P. LOND., HOUSE PHYSICIAN AND RESIDENT ANASTHETIST, LONDON HOSPITAL; AND

H. S. SOUTTAR, M.A., M.CH. OxON., F.R.C.S. ENG., SURGICAI REGISTRAR, LONDON HOSPI'PAI.

IT has long been recognised that paraldehyde is in many ways the most perfect hypnotic we possess. In certainty of action it is unsurpassed, while its stimulating effect upon respiration and circulation and its absence of after-effects are in marked contrast to the depression, immediate and remote, produced by other hypnotics. Given by mouth its taste is a serious disadvantage, and the preliminary excitement it may sometimes cause is undesirable. It appeared to us that these defects could be largely overcome by intravenous injection, and the results of our experiments have exceeded our expectations. The hypnotic effect is the most perfect we have ever seen, being exceedingly rapid and yet devoid altogether of unsatisfactory circumstances. The patient appears both to himself and to onlookers to pass into a perfectly natural and easy sleep. Respiration deepens, the pulse is slower and fuller, the colour is absolutely unaltered. Yet if the injections be continued deep anæsthesia can be produced with great rapidity. This latter fact opens up a wide field upon which we hope shortly to make a further communication. Here we shall restrict ourselves to the use of paraldehyde intravenously as a hypnotic or as an anæsthetic for minor operations.

Paraldehyde is a colourless volatile liquid with a characteristic and unpleasant taste and smell. Its specific gravity is 0.998 , it is soluble in ten volumes of water at $15^{\circ} \mathrm{C}$. less soluble in hot water, and boils at $124^{\circ} \mathrm{C}$. It i miscible in all proportions with ether and alcohol. Under ordinary circumstances it has no depressing effect upon the heart. Intravenously we found it to act momentarily as a depressant. 'This effect is transient and can be entirely eliminated by combining in the injection an equal amount of ether. The action of paraldehyde is so rapid that we preferred to retard it by dilution. We therefore mix 5 to 15 c.c. of paraldehyde with an equal amount of ether and dissolve the mixture in 150 c.c. of a cold 1 per cent. solution of sodium chloride in sterile distilled water free from dead bacteria, o in default of this in ordinary boiled tap water. The solution should be perfectly clear after shaking. It is placed in a sterile bottle with a rubber stopper through which pass two glass tubes. To one of these tubes bellows are attached. The other reaches to the bottom of the liquid and leads off by a long rubber tube to a fine hypodermic needle. The apparatus we have used is that derised by Fildes and McIntosh for the injection of salvarsan. The solution may 